\title{
An overlooked factor in duodenal ulceration and postoperative recurrence?
}

Intraluminal acid is usually accepted as the paramount damaging agent in chronic peptic ulcer, as decreasing its secretion, diluting it, neutralising it, or diverting it from contact with an ulcer all induce healing. Inconsistently, many peptic ulcers develop in the absence of gastric acid hypersecretion and most of the gastroduodenal mucosa resists intraluminal acid attack, while but a small, usually solitary and predictable area succumbs. ${ }^{12}$

Either there is localised acid attack or localised reduction in mucosal resistance. There is no localisation of intraluminal acid attack ${ }^{3}$ and when gastroduodenal mucosa is exposed experimentally to excessive intraluminal acid, multiple scattered ulcers develop, as would be expected. ${ }^{4}$ Perhaps localised mucosal damage determines the site of ulcers? Duodenitis and antral gastritis are regularly associated with duodenal ulcer and may precede it. $^{56}$

Ulceration is by no means inevitable, however, and when it occurs the main area of gastritis survives. Chronic ulcers develop only at the proximal or distal ends of the segment of gastroduodenitis, producing gastric and duodenal ulcers respectively, where the damage may be most recent and active. $^{7}$

The implication of Campylobacter pylori in duodenal ulceration is uncertain. ${ }^{8}$ This microorganism appears to be a marker for active chronic gastritis, which is patchy in its distribution. ${ }^{9}$ Gastric mucosal cells alone are colonised either in the stomach or in areas of gastric metaplasia in the duodenum. ${ }^{10}$ Such metaplastic areas are regularly seen in the duodenal bulb. ${ }^{11-13}$ Elimination of $C$ pylori favours duodenal ulcer healing and protects against recurrence. ${ }^{14}$ Thus the assocíation between $C$ pylori and duodenal ulcer is close. ${ }^{15}$ When gastroduodenal colonisation occurs, however, it is scattered and its putative damaging effect should be dispersed, resulting in multiple ulcers. In contrast chronic duodenal ulceration is discrete and predictably sited.

It would clarify the enigma of peptic ulcer if it always occurred in the first susceptible mucosa to come into contact with freshly secreted acid that has not yet been partially diluted, adsorbed, absorbed, and neutralised. Gastric, oesophageal, and anastomotic ulcers develop in close proximity to fundic mucosa but duodenal ulcer occurs at a distance from it.

Parietal cells are not limited to the fundus, however, and their presence in the duodenum is well documented, ${ }^{16-18}$ especially in patients with duodenal ulceration. Parietal cells may be found on one side of a tubule lined on the opposite side by intestinal cells. ${ }^{16}$ Most authors consider the presence of gastric cells in the duodenum to be a protective response to hyperacidity ${ }^{19}$ but a more logical and contrary explanation would be that the distal extension of fundic mucosa is the cause of the increase in acid secretion. ${ }^{7}$ Tominaga ${ }^{20}$ found parietal cells in the antra of all but $2 \%$ of normal subjects 
and in $90 \%$ there is a concentration of these cells just proximal to the pyloroduodenal junction. Thus, fresh, locally secreted acid may come into contact with intestinal cells, perhaps within the mucosa. This could explain the apparent anomaly of the relation of duodenal ulcers to the gastric fundus.

The importance of locally secreted, perhaps intramucosal, acid in the progression of peptic ulceration might also explain why mucosa that has withstood attack from intraluminal acid succumbs as it is drawn into the edge of a chronic peptic ulcer. The crater remains small because of wound contraction but the area that is progressively destroyed may be very large. In teapot stomach most of the lesser curve is eroded, in hourglass stomach most of the gastric circumference has disappeared. Even in duodenal ulceration, an area of up to $9 \mathrm{~cm}^{2}$ may be lost. ${ }^{21}$

The presence of pyloric and duodenal parietal cells is not taken into account in the operation of proximal gastric vagotomy, in which the fundic region of the stomach alone is denervated, resulting in a $70 \%$ reduction in pentagastrin stimulated acid output,,$^{22}$ comparable with the effects of other operations. The duodenal ulcer recurrence rate appears to exceed that of the other techniques, however, especially with the passage of time.$^{23} \mathrm{~A}$ recent report from a specialist centre records a $30 \%$ recurrence after a 14 to 18 year follow up. ${ }^{24}$ Duodenal ulcers that fail to respond to $\mathrm{H}_{2}$ receptor antagonists have a higher recurrence rate after proximal gastric vagotomy than ulcers that do respond to treatment with the drugs. ${ }^{25}$ It is possible that the innervated pyloroduodenal parietal cells continue to secrete fresh, locally damaging acid, even though the gradual rise in intraluminal acid ceases after five years. ${ }^{23}$

Royal Free Hospital,

R M KIRK

Pond Street,

London NW3 2QG

\section{References}

1 Kirk RM. Can the singularity of peptic ulcers be described by catastrophe theory and explained by biofeedback? Gastroenterology 1977; 73: 608-10.

2 Kirk RM. Factors determining the site of chronic gastroduodenal ulcers. Hepatogastroenterol 1982; 29: 75-85.

3 Kirk RM. Does the jet emerging through the pylorus determine the site of duodenal bulbar ulcers? Br Med J 1975; 3: 629-30.

4 Parker PE, Soergel K, Ellison EH. Effects of excessive hydrochloric acid on the canine gastrointestinal tract. Surg Forum 1963; 14: 333-4.

5 Meikle DD, Taylor KB, Truelove SC, Whitehead R. Gastritis, duodenitis, and circulating levels of gastrin in duodenal ulcer before and after vagotomy. Gut 1976; 17: 719-28.

6 Greenlaw R, Sheahan DG, Deluca V, Miller D, Myerson D, Myerson P. Gastroduodenitis: a broader concept of peptic ulcer disease. Dig Dis Sci 1980; 25: 660-72.

7 Kirk RM. Could chronic peptic ulcers be localized areas of acid susceptibility generated by autoimmunity? Lancet 1986 ; i: 772-4.

8 Marshall BJ, McGechie DB, Rogers PA, Glancy RJ. Pyloric campylobacter infection and gastroduodenal disease. Med J Aust 1985; 142: 439-44.

9 Hazell SL, Hennessy WB, Borody TJ, et al. Campylobacter pyloridis gastritis: II. Distribution of bacteria and associated inflammation in the gastroduodenal environment. Am J Gastroenterol 1987; 82: 297-301.

10 Steer HW. Surface morphology of the gastroduodenal mucosa in duodenal ulceration. Gut 1984; 25: 1203-10.

11 James AH. Gastric epithelium in the duodenum. Gut 1964; 5: 285-94. 
12 Patrick WJA, Denham D, Forrest APM. Mucous change in the human duodenum: a light and electron microscopic study and correlation with disease and gastric acid secretion. Gut 1974; 15: 767-76.

13 Kreuning J, Bosman FT, Kuiper G, Lindeman J. Gastric and duodenal mucosa in 'healthy' individuals; an endoscopic and histopathological study of 50 volunteers. J Clin Pathol 1978; 31: 69-77.

14 Coghlan JG, Gilligan D, Humphries H, et al. Campylobacter pylori and recurrence of duodenal ulcers - a 12 month study. Lancet 1987; ii: 1109-11.

15 Dooley CP, Cohen H. The clinical significance of Campylobacter pylori. Ann Intern Med 1988; 108: 70-9.

16 Leela K, Kanagasuntheram R. A microscopic study of the human pyloroduodenal junction and proximal duodenum. Acta Anat 1968; 71: 1-12.

17 Hoedemaeker PJ. Heterotopic gastric mucosa in the duodenum. Digestion 1970; 3: 165-73.

18 Johansen A, Hart Hansen O. Heterotopic gastric epithelium in the duodenum and its correlation to gastric disease and acid level. Acta Pathol Microbiol Scand 1973; 5: 676-80.

19 Rhodes J. Experimental production of gastric epithelium in the duodenum. Gut 1964; 5: 454-8.

20 Tominaga K. Distribution of parietal cells in the antral mucosa of human stomachs. Gastroenterology 1975; 69: 1201-7.

21 Kirk RM. The contribution of wound contraction to the healing of peptic ulcers. In: Hollender LF, D’Onofrio G, eds. Digestive surgery. Padova: Piccin, 1974: 57-8.

22 Johnston D, Wilkinson AR. Highly selective vagotomy without a drainage procedure in the treatment of duodenal ulcer. Br J Surg 1970; 57: 289-96.

23 Stael von Holstein C, Graffner H, Oscarson J. One hundred patients ten years after parietal cell vagotomy. Br J Surg 1987; 74: 101-3.

24 Hoffman J, Olesen A, Jensen H-E. Prospective 14- to 18 year follow-up study after parietal cell vagotomy. Br J Surg 1987; 74: 1056-9.

25 Primrose JN, Axon ATR, Johnston D. Highly selective vagotomy and duodenal ulcers that fail to respond to $\mathrm{H}_{2}$ receptor antagonists. Br Med J 1988; 296: 1031-5. 